Vol.15, No. 57, October, 2020, 992-1002

\title{
ENHANCEMENT OF CONCRETE ELEMENTS AND ITS EFFECT ON NATURAL LIGHTING
}

\author{
Sara N. Elkabany ${ }^{1}$ * Ahmed Mohamed Elkordy ${ }^{2}$, and Hesham Ahmed Sobh ${ }^{2}$ \\ ${ }^{1}$ Architecture Department, Faculty of Engineering(Girls), Al-Azhar University, Cairo, \\ Egypt. \\ ${ }^{2}$ Architecture Department, Faculty of Engineering, Al-Azhar University, Cairo, Egypt. \\ *Corresponding Author E-mail: sara.alkabany@azhar.edu.eg
}

\begin{abstract}
:
this paper proposes to study the role of structural elements in buildings for functional, aesthetic aspects and lighting and Interest in the optimization of the structural system for loadbearing walls of concrete to increase the external lighting openings and reduce the cost while enhancing the strength of concrete as well as reducing its density. The problem lies in the fact that the bearing walls of the walls have less use of lighting openings in addition to the high cost due to the use of the traditional process of design without use optimization processes of design as they have a major role in reducing the cost while maintaining the aesthetic required. During this study, this accomplished through analyzing the case studies of the broad museum building and the Victoria Gate where different types of concrete used. SolidThinking Inspire used to create the study model using the morphology tool. The design of the model depends on the algorithm for optimization of the topology, and the optimization models compared with the case studies selected before the improvement process in terms of shape, increase in stiffness, the difference in density, and area of the lighting openings. The optimization results found to be effective and designed with the highest strength to prevent deformation that reflected in the increase in lighting openings and reduce cost.
\end{abstract}

KEYWORDS: Optimization, 3D Printing, Concrete, Cost, Lighting Openings.

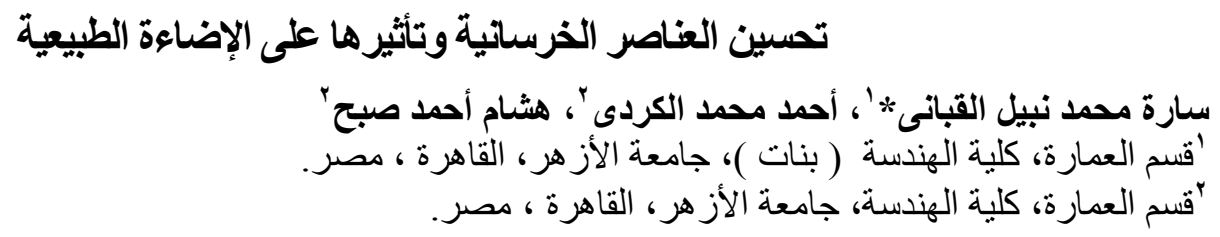

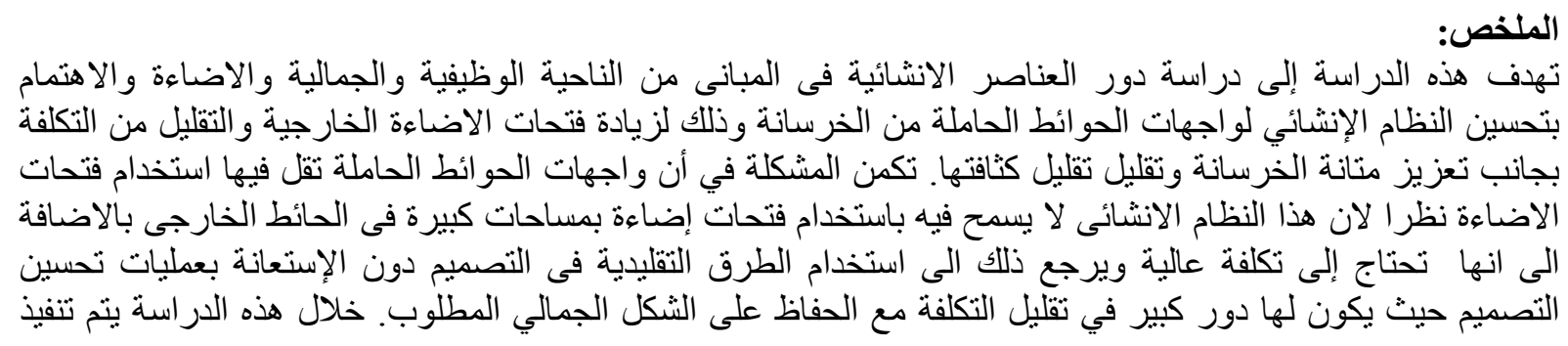




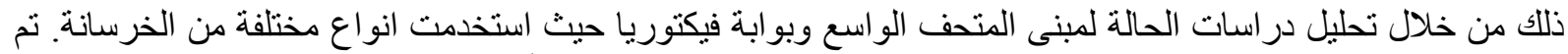

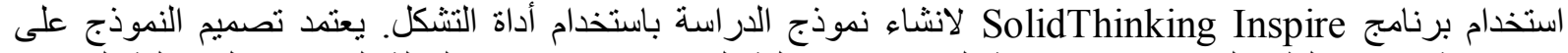

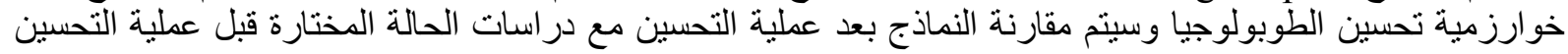

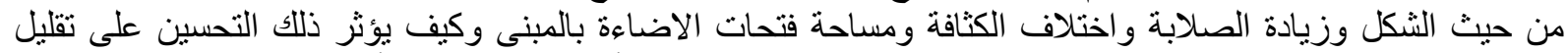

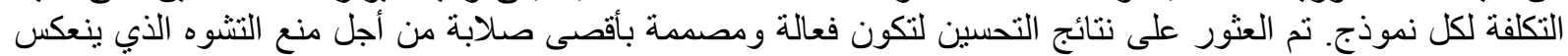
بوضوح في زيادة فتحات الاضاءة ونور وتقليل التكلفة خلال مر احل التصميم الأولية.

الكلمات المفتاحية : تحسين ، الطباعة ثلاثية الأبعاد، الخرسانة، التكلفة، فتحات الإضاءة.

\section{INTRODUCTION}

The structural form directly affects the areas of the lighting openings in the building facades. Thus, the process of enhancing the shape and characteristics of the load-bearing wall of hardness and low weight helps directly in increasing the natural lighting openings of the building. In the past decade, the use of structural optimization has increased rapidly. The upstream phases of the design process account for 5 percent of the time spent on product development but represent 75 percent of the global development costs (Sharpe JEE, 1995).

This is critical when bringing optimization into a project's early stages. It has become important to use Algorithms to refine the goods to check that materials and shapes. Through developments in computer science and technology, structural engineering modeling has become one of the most critical means of achieving lightweight, high-performance structures. Structural optimization usually divided into optimization of scale, form, and topology, based on the various architecture variables. Topology optimization was deemed the most common of these three optimization approaches as it can provide engineering designers with fresh and often even unexpected concepts without needing a pre-established plan. Optimization of topology, in general, uses optimization methods to seek to figure out where to put the material in the architecture environment (Bendsøe, Sigmund, 1999). Topology optimization has experienced rapid growth over the past four decades and has been extended effectively to structural architecture in many manufacturing fields, including the automobile, aerospace, and biomedical industries (Zhu, Zhang, Beckers, 2009).

Many different approaches are suggested for optimization of topology, including the density system (Liu, Hu, Li, Zhou, Dong, 2014), it is among these approaches the evolutionary approaches Bi-directional Evolutionary Structural Optimization (BESO) and Evolutionary Structural Optimization (ESO), and Bi-directional evolutionary Structural Optimization (BESO) (Xie, Steven, 1993). Among such methods, the density approach used to define the structural topology by using element-constant density is the most advanced methodology owing to its computational stability and efficiency.

\section{FORMULATION OF PROBLEM}

Optimization of shape, function, and substance in architectural models as distinct areas has culminated in the wasteful usage of structural materials in architectural designs (Oxman, 2010). Enhanced design and structural efficiency is necessary to integrate framework, design, and shape into a single feature load-bearing wall-and to overcome the issue of facade positioning and to avoid the use of substructures and structural barriers inside facades In addition to improved natural lighting.

The application used aims to add the mechanical properties and behavior of load-bearing walls in the early stages of design by developing their functional and structural performance, and their direct impact on the lowering expenses, and increasing lighting openings that contribute to increasing the proportion of natural lighting. The technology used in the optimization process is a set of metrics defined within the application (shape support cases loads - openings size).

\section{ROLE OF STRUCTURE IN INCREASING NATURAL LIGHTING}

To increase daylight levels and to increase transparency through the building's envelope, the architects make some modifications to the structural details. The lighting can be an increase in 
interior space and using natural lighting by reducing the size of the structural elements and creating openings in them that allow the passage of natural light within the internal space of the building.

\subsection{Breakthroughs in Structural Elements}

Breakthroughs in structural elements are one aspect of structural detail. Sometimes the details require a greater amount of natural lighting. Breakthroughs in structural elements give it lightness and increase the amount of natural light. It is an increasingly popular technology that it gives for the lightness more than a source of natural light. In general, windows and openings breakthroughs the concrete walls, but when lighting is more important than visibility, making smaller, more numerous breakthroughs is more appropriate (Michael \& Ashby, 1999).

At the Mexican Embassy in Berlin, the main cylindrical lobby is behind the embassy facade, where the outer wall forms a part of the concrete cylinder surrounded by daylight, carved with circular holes that give the concrete wall a lightweight feel and increasing of the natural light shown in Fig. 1.

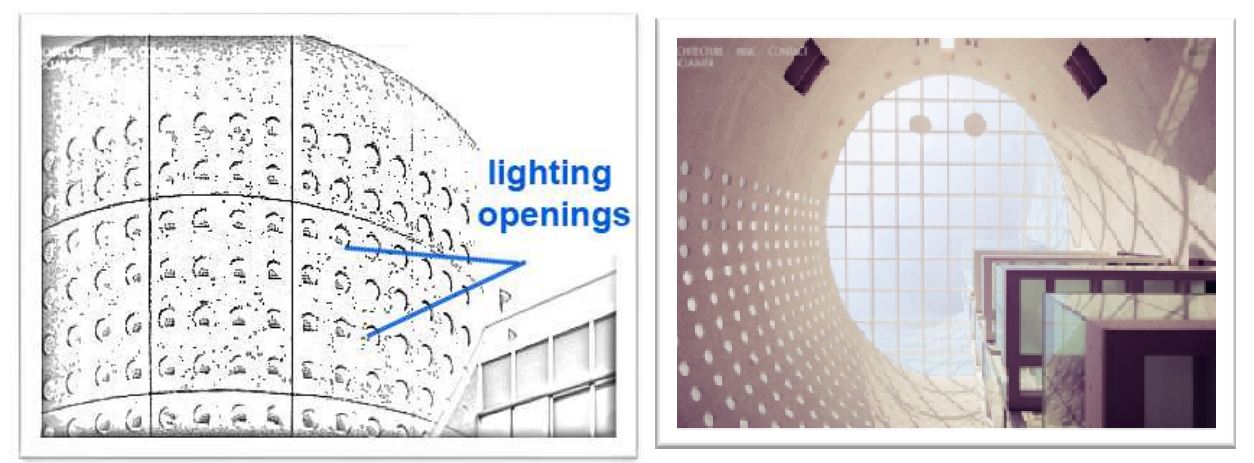

Fig. 1: The Mexican Embassy in Berlin (Jan Rottler, 2019)

\subsection{Modify For Lighting}

The structure is not only a source of light but sometimes is designed to increase the amount of light inside the building or to adjust the intensity and quantity of light. The structure can also obscure the light with its opacity, or the structure can be used to light or reverse the light.

\subsubsection{Filter of Light}

The many structural elements located in layers and close spaces have the property of filtering the light inside the place.

For example, the internal structure of the ceiling of the listening hall at the Wolen High School Auditorium see Fig. 2 The roof plays a strong role in filtering light through the upper glass between structural elements, where the functional role of the main arches is a filter for light, giving the reflection of natural and artificial light in different lighting conditions (Zajonc, 2006).

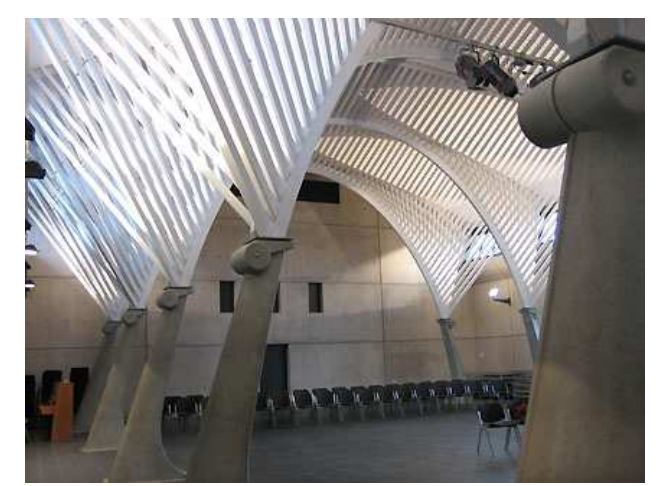

Fig. 2: Wolen High School Auditorium (Galinsky, 2006) 


\subsubsection{The Structural Elements Reflection of Light}

The structural elements block direct sunlight, but they can also reflect and spread it into the surrounding spaces. In the Monchengladbach Museum, the ceiling parts of the museum receive a large direct light. Because of its light color, it plays an influential role in blocking sunlight and reversing it into the spaces of the display see Fig. 3, (Andrew, 2005).
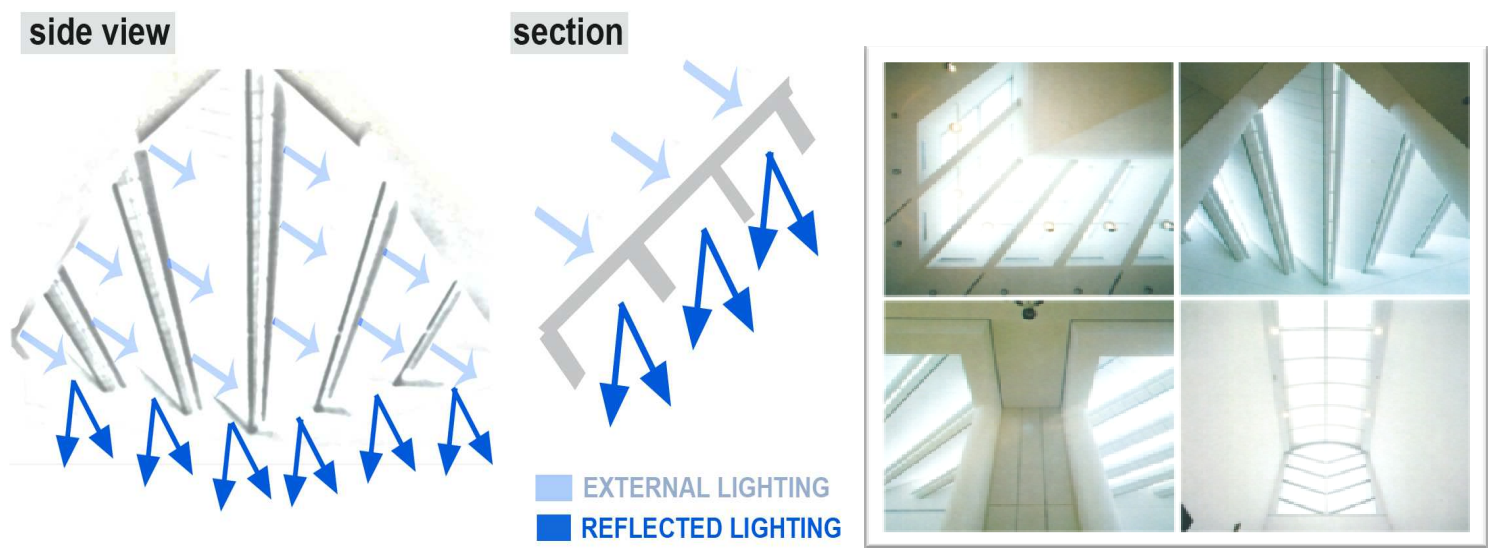

Fig. 3: Ceiling of Mönchengladbach Museum by Architect Hans Hollein (Rykwert, 2014)

In the expansion of the Denver Museum of Art by architect Daniel Lipskend, and it's an exhibition of contemporary art collections, architectural collections, and spatial art. It is a building of reinforced concrete and clad with titanium, the structural elements on the ceiling receive direct sunlight and spread it inside the space to reflect it artistically, so the light becomes part of the show inside the museum. In Fig. 4, illustrates the optical experiments provided by structural elements in the reflection of natural light. "One of the challenges at the Denver Museum is responding to the changes in the wide range of lighting, color, surrounding influences and the distinctive climate in this city, and I emphasize the integration of these elements not only functional and physical but also cultural and add fun experiences to benefit a museum visitors," says Lipskind. The architect used the structural elements of the ceiling and walls to modify the natural light that penetrates the interior spaces through the specific glass surface, intertwined with the solid structural elements (Elizabeth, 2009).
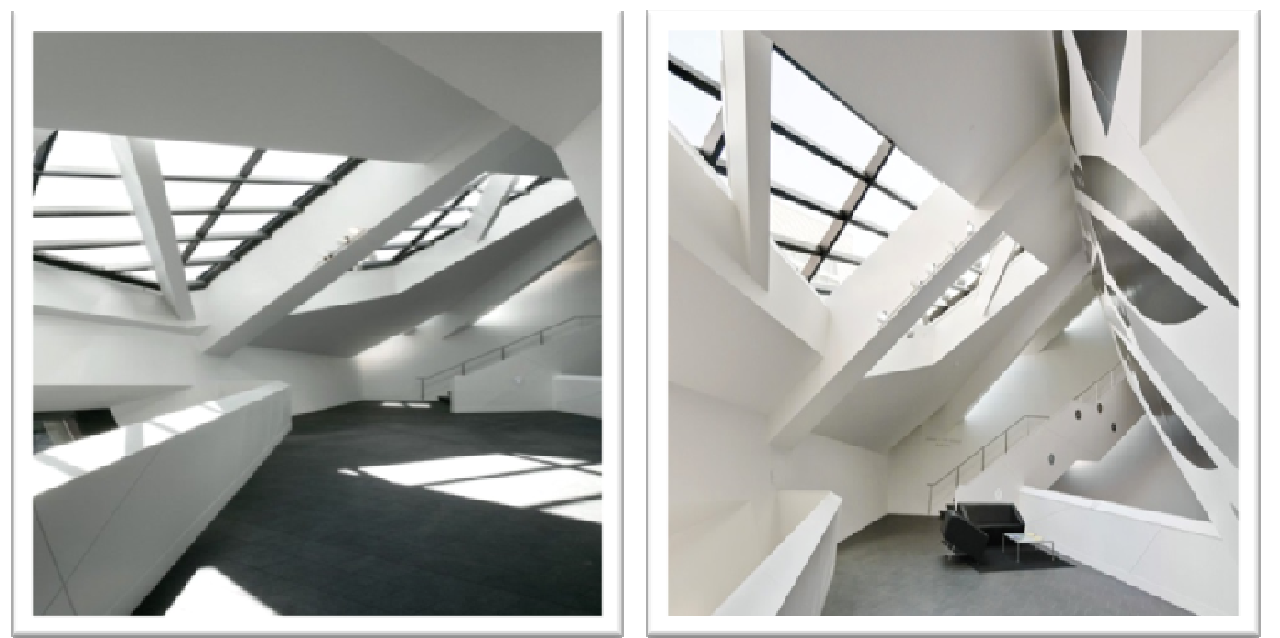

Fig. 4: The Denver Museum of Art (ArchDaily, 2020)

The textile properties have the characteristic of reversing and diffusing light. Their glossy and white surfaces, except for the sun-warmed dark tissues, ensure a high degree of reflection. The fabric's ability to diffuse and diffuse light tested on a sunny day. The transparency varies according to its thickness and quality, Low, and stable comfort. 


\subsection{Light Modifies the Visual Size of the Structural Elements}

Often the structural elements control the quality and quantity of lighting inside the building, but the light relation is not entirely influenced by structural elements, as the light reveals the details of the structural elements as it modifies the human perception of its size. The phenomenon of non-enactment occurs when areas of the structure exposed to higher degrees of illumination than ambient light, to the extent that they lose their shape in the blurry brightness. The columns that continue through the windows represent this situation in the wooden Showroom Hergatz where the wooden columns passing through the windows are lighting when the sun is bright so that they merge with the total brightness in the background and the columns look as if they are not attached to the ground and stand at the top of the window line, But this visual effect becomes unnoticeable on a hazy day see Fig. 5, (Charleson, 2015).

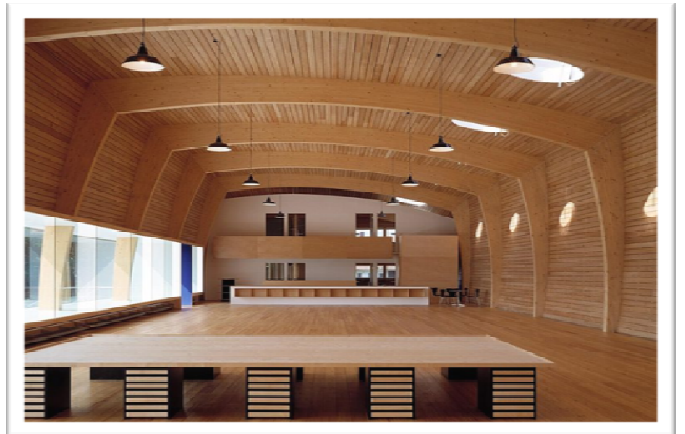

Fig. 5: Showroom Hergatz (Baumschlager architekten, 2019)

In the internal structure of the Church of Benedict, we find a similar effect to the exegesis in the previous example using lighting as the columns pass in front of the upper windows of the church and the brightness of the surfaces and glow, which reduces the clarity and intensity of shades, Reinforcing the belief that the roof is floating see Fig. 6.

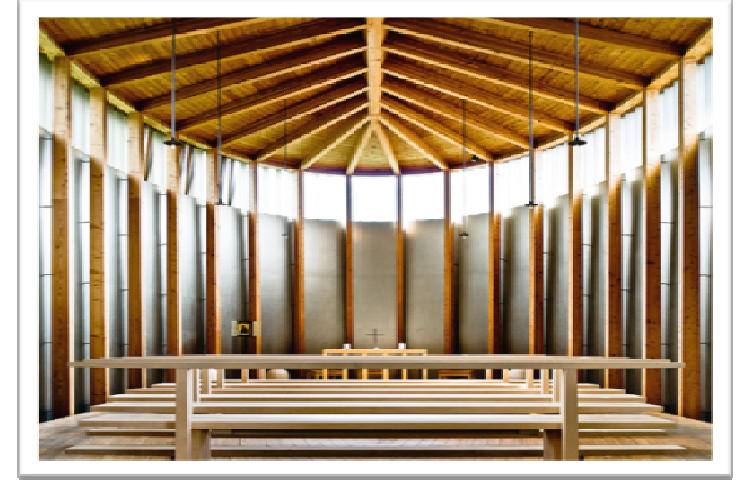

Fig. 6: Benedict Chapel Saint (Peter Zumthor, 2020)

\section{OPTIMIZATION PROCESS OF STRUCTURE}

From the above, we note that the external structure in the buildings has a great role in determining the features of the building and its shape, as well as determining the amount of natural light and how to direct it inside the building through the size of lighting openings, especially in the load-bearing walls. So it was necessary to make an optimization for this type of buildings in order to reach the best form of the structural elements at the lowest cost, in addition to optimizing the lighting openings and providing maximum natural lighting for the building.

\subsection{Software and Material Selection}

Technological advances in parametric modeling make it possible to influence the large-scale processing of complex forms. Using a generative series and the interaction between geometric artifacts, the parametric architecture method introduces meaning to a geometric paradigm.

Reinforced concrete provides tensile strength, such as steel plates, and is immune to physical impacts (Wilfredo Méndez, 2019), Where all substrates are composite and isotropic, 
SolidThinking Inspire 2019 load-bearing wall modeling software is the preferred program. The use of a morphology instrument focused on the design of topology and parametrics, which are often complex forms and difficult to design. Shape Optimization creates efficient structures of lightweight that meet the demands of weight, strong performance.

\subsection{Portion Weight Calculations}

This optimization focuses on the structure dimensions $11 \mathrm{~m} \times 7 \mathrm{~m}$ for the case studies where the 3D printing machine model size is $22 \mathrm{~cm} \times 14 \mathrm{~cm}$ (All3DP team, 2020), a scale used in the optimization process is 1:50. The weight and resistance of the structures compared to the selected case studies.

\subsection{Case Studies Selection}

The chosen Case studies of structures are (Victoria Gate, And the Broad Museum). Table 1, shows the section of study form that will be optimization is $7 \mathrm{~m} \mathrm{x} 11 \mathrm{~m}$, in (Victoria Gate) the density white concrete $3150 \mathrm{~kg} / \mathrm{m} 3$, whereas in (Broad Museum) the density concrete1800 $\mathrm{kg} / \mathrm{m} 3$, it is used for panels made from fiberglass-reinforced concrete martial (Shakor, Pimplikar, 2011).

Table 1: Calculations of Victoria Gate Building and the Broad Museum Building

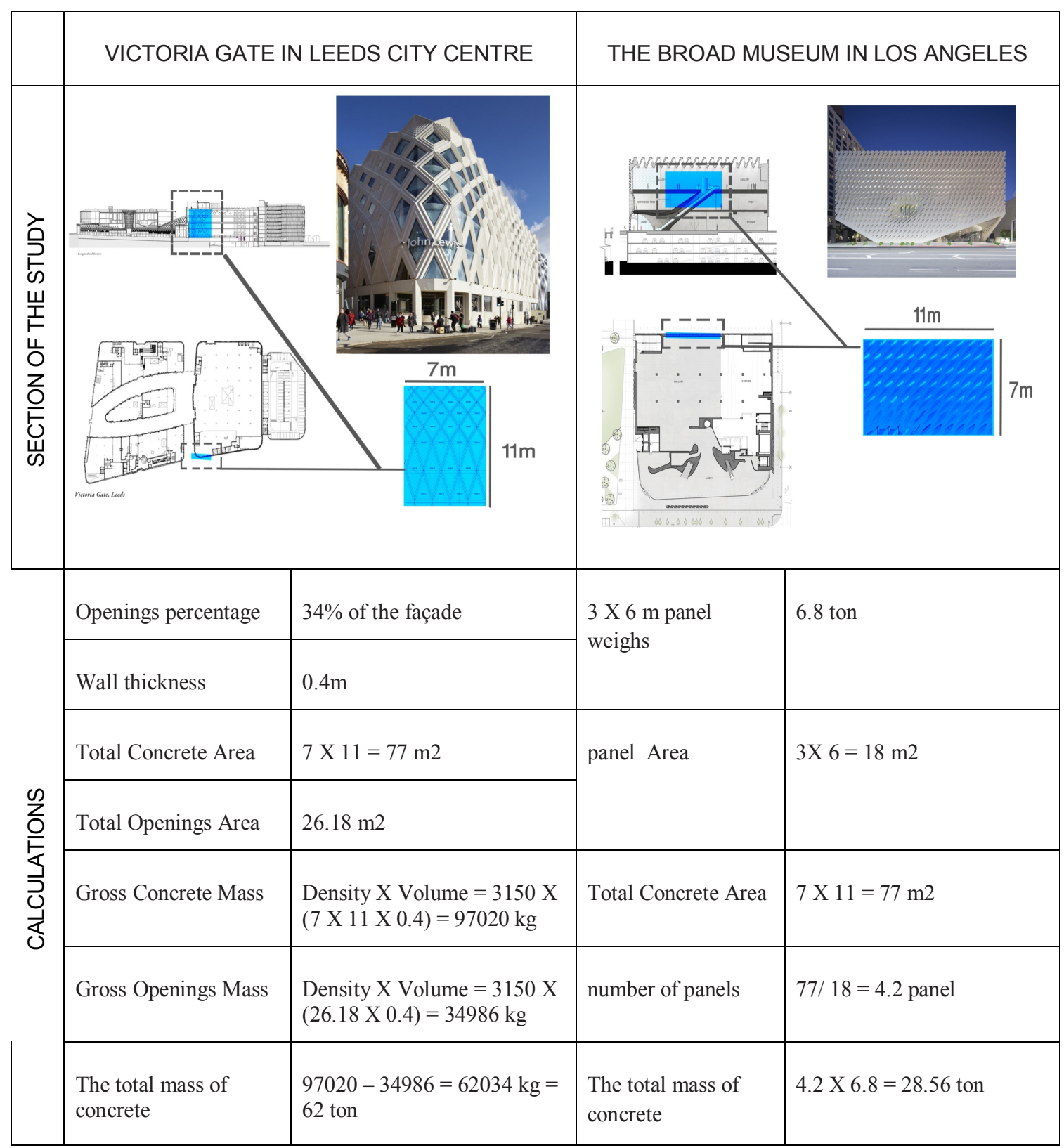




\section{4. Solidthinking Inspire Outputting Model}

The following Table 2, summarizes the comparative results of the material optimization and structural quality contrast factors between the models produced by solidthinking inspire software and the case study design of the buildings and produce models of 3D printed with a lower density ratio for the materials used and how the optimization affected the form of the wall by increasing the lighting openings area. after the optimization process, the biggest decrease was in the first case, white concrete material, and then comes the second case which used Fiberglass Reinforced Concrete material, which indicates that the use of improvement differs from one substance to another, Where optimization occurs at the maximum degree for untreated conventional materials, which results in a decrease in density and therefore a reduction in cost.

Table 2: Comparison of Material, Structural Efficiency, and 3D Printed models before and after optimization For Case studies

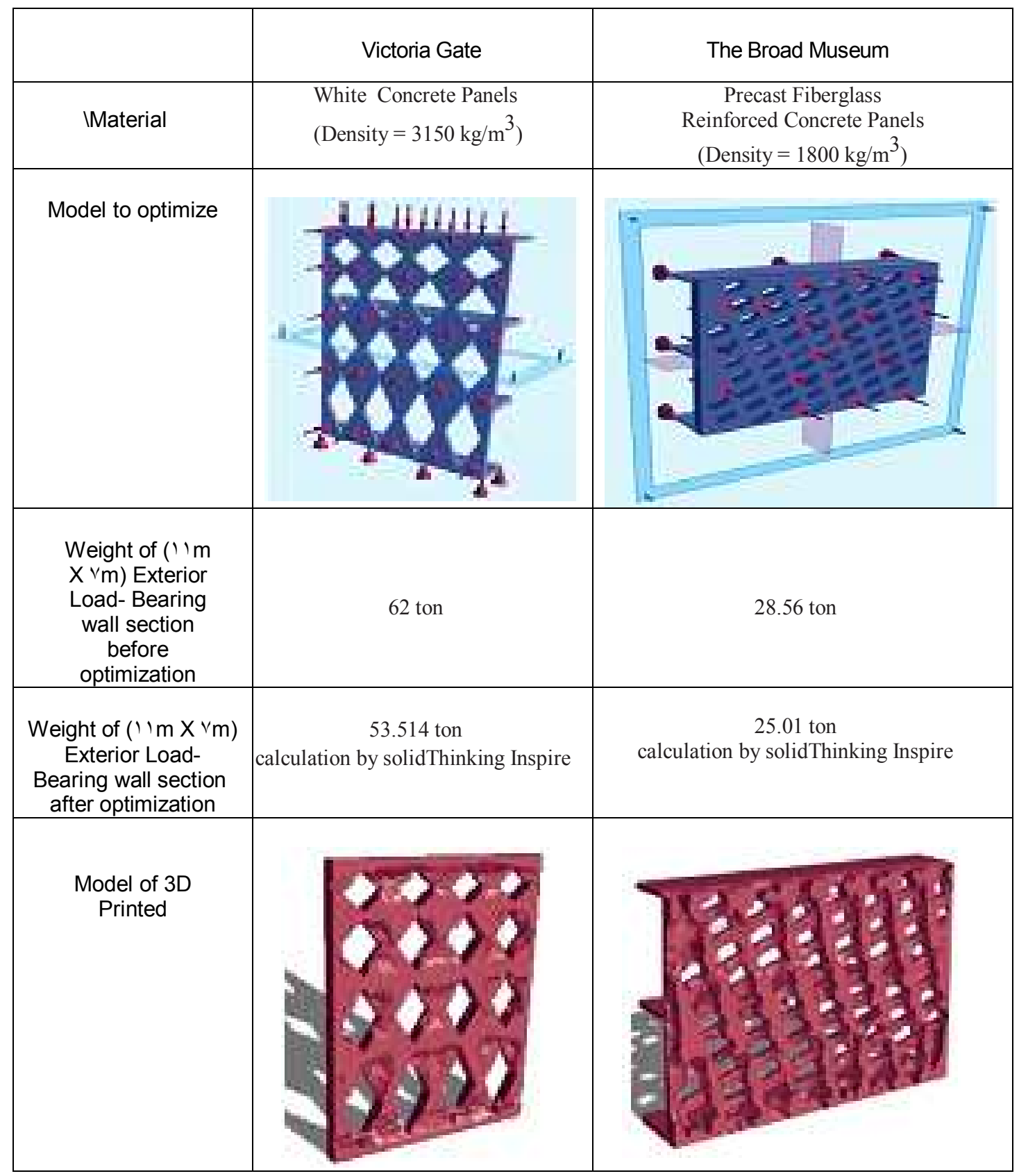




\section{RESULTS AND DISCUSSION}

Through the analytical study of the previous examples, see Fig. 7, which explains the role of structure and lighting:

\section{THE ROLE OF STRUCTURE AND LIGHTING}

Architectural elements are essential, dependent on each other, while the construction controls the entry sites of light of the building and the quantity and quality, However, the need for natural lighting inevitably determines the structural form that must be followed with its details - whether light or heavy. The quantity and quality of lighting required for the building are governed by the structural decisions during the design process. After construction, the base is reflected and the construction is controlled by light.

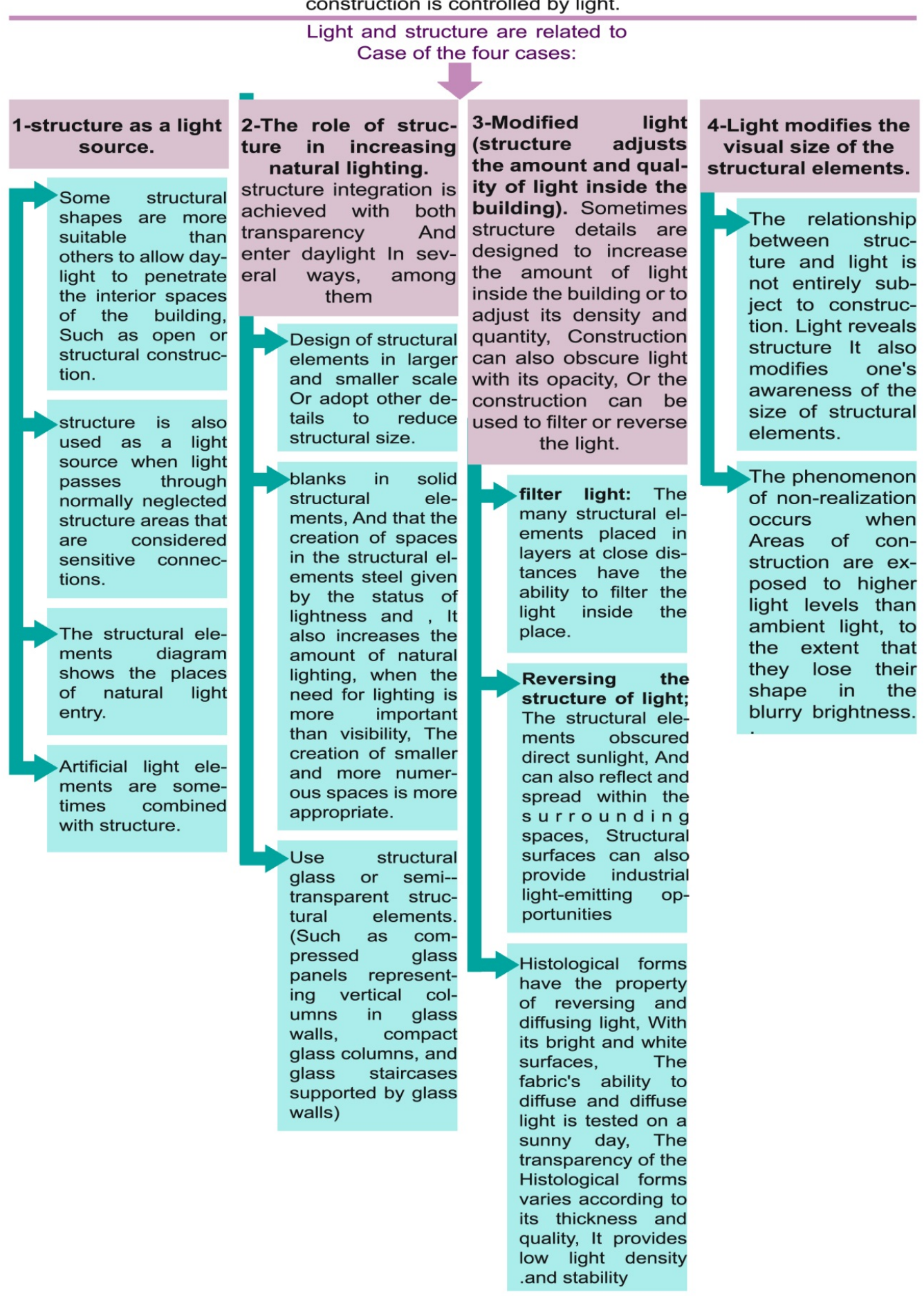

Fig.7: The Role of Structure and Lighting. 
The goal of the improvement was to optimize hardness to achieve the lowest density of the material and thus the lowest cost while maintaining the shape and preventing deformation besides having more space for the lighting openings. The structural wall optimization offers mechanical properties where a structure weights $13 \%$ less than equivalent cases before optimization. You will find the increase in the percentage of lighting openings, the lower the percentage weight of the materials used, where in the first case, the rate decreased by $13.7 \%$ from 62 tons to 53.514 tons, in the second case it decreased by $12.4 \%$ from 28.56 tons to 25.01 tons. Lighting openings percentage of total mass before and after optimization in the first case from $34 \%$ to $47.7 \%$ and in the second case from $30 \%$ to $42.4 \%$ as shown in Table 3 and Fig. 8.

Table 3: Percentage of Materials used for Maximum Strength, Less Weight and more Lighting Openings

\begin{tabular}{|c|c|c|c|c|}
\hline Projects Martial & $\begin{array}{c}\text { Weight rate } \\
\text { before } \\
\text { Process } \\
\text { Optimization }\end{array}$ & $\begin{array}{c}\text { Weight rate } \\
\text { after } \\
\text { Process } \\
\text { Optimization }\end{array}$ & $\begin{array}{c}\text { Percentage } \\
\text { of reduce } \\
\text { material } \\
\text { weight }\end{array}$ & $\begin{array}{c}\text { Lighting } \\
\text { openings } \\
\text { percentage of } \\
\text { total mass } \\
\text { before } \\
\text { Optimization } \\
\text { openings } \\
\text { of total mass } \\
\text { after } \\
\text { Optimization }\end{array}$ \\
\hline $\begin{array}{c}\text { Victoria Gate } \\
\text { White Concrete Panels }\end{array}$ & 62 ton & 53.514 ton & $13.7 \%$ & $34 \%$ \\
\hline $\begin{array}{c}\text { The Broad Museum } \\
\text { Fiberglass Reinforced Concrete Panels }\end{array}$ & 28.56 ton & 25.01 ton & $12.4 \%$ & $30 \%$ \\
\hline
\end{tabular}

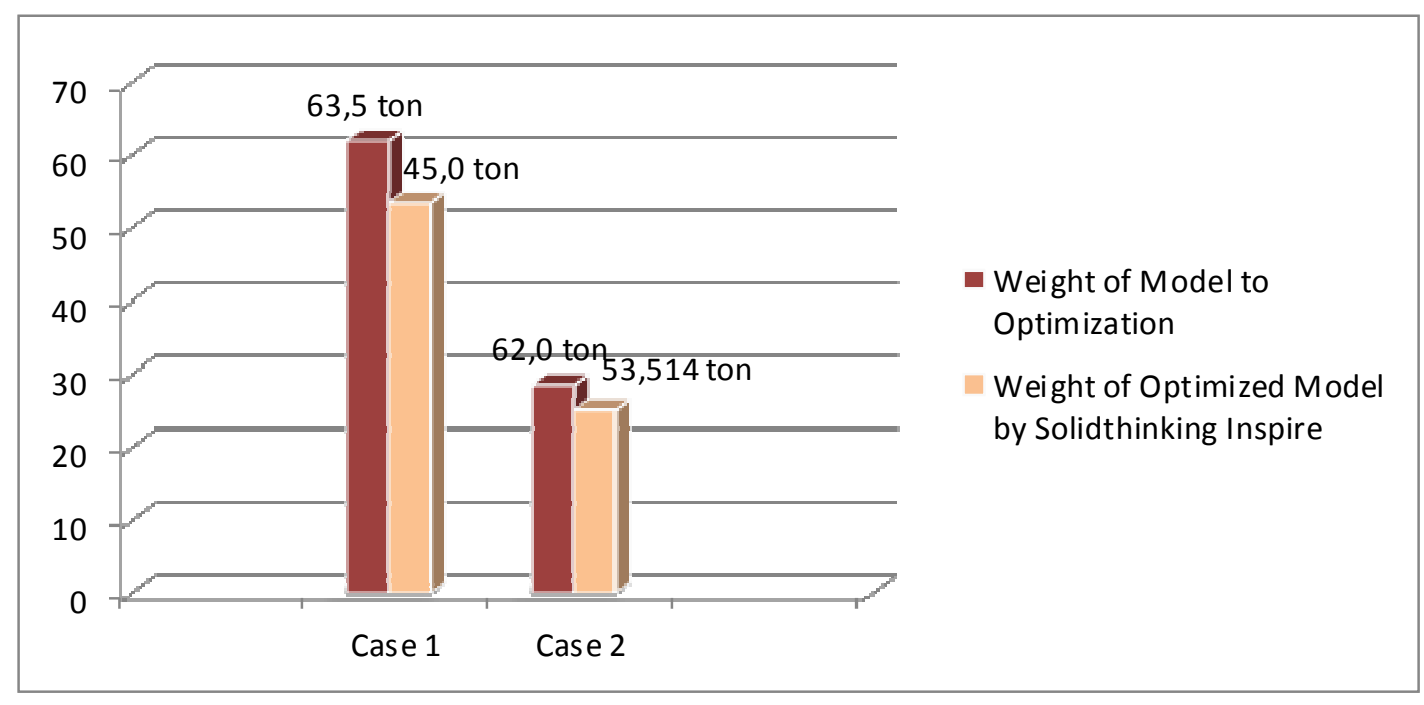

Fig. 8: Reduce Weight of Load-Bearing Wall after Process Optimization.

\section{SUMMARY AND CONCLUSIONS}

- The relationship between structure and lighting is not entirely subject to the structure. The light reveals the structure as it modifies realize of the structural size elements clearly, so if studying natural lighting professionally, it reduces the severity of the structural elements.

- Non-embodiment phenomenon occurs when areas of the structure exposed to greater degrees from lighting to the point that they lose their specific form in fog brightness.

- The use of the software makes it possible to develop a wide range of structural solutions and their performance for the natural lighting function of the building.

- Use of mechanically engineered actions on the load-bearing wall in the early stages of architectural design to create its content and structural efficiency; The approach used to 
address the problem is to combine increasing of the established parameters such as load instances, supports, the volume of construction and materials:

1) Scale dimension for the Maximum 3D printing system is $14 \times 22 \mathrm{~cm}$, maintain a scale of 1:50; a $7 \times 11 \mathrm{~m}$ section of the structural skin was analyzed during the experimental test.

2) The structural wall surface is modeled and developed with software (solidthinking inspire) using a topology optimization algorithm.

3) The optimization of mechanical properties on the structure wall surface gives a structure, which is $13 \%$ less in weight and more in lighting openings than the comparable cases.

4) The usage of content enhancement algorithm systems has a direct connection between shape and functionality. As for the improvement of white concrete, it resulted in lower density, hardness, and better surface quality than fiberglass-reinforced concrete. White concrete used to build lightweight structures after improvement, which is more structurally functional.

\section{REFERENCES}

1. All3DP team, 2020. Best Large-Format 3D Printers, URL https://all3dp.com/1/bestlarge-3d-printer-large-format-scale-3d-printers/

2. Andrew Charleson, 2015, Structure as Architecture, A source book for architects and structural engineers, P. 127.

3. ArchDaily, 2020. Mexican Embassy Berlin, URL https://www.archdaily.com/80309/denver-art-museum-daniel-libeskind

4. Arthur Zajonc, 2006. Daylight \& Architecturemagazine Byvelux, Pp. 3-9.

5. Baumschlager Eberle Architekten, 2019. Holz Altenried, Hergatz, URL https://www.baumschlager-eberle.com/en/work/projects/projekte-details/holzaltenried/

6. Bendsøe MP, Sigmund O, 1999. Material interpolation schemes in topology optimization. Arch Appl Mech, P. 54.

7. Charleson. Andrew, 2005. Structure as Architecture, Architectural Press, P. 169.

8. Galinsky, 2006. Wohlen High School, URL http://www.galinsky.com/buildings/wohlen/index.htm

9. Hunt. Elizabeth Gay, 2009. Study of Museum Lighting and Design, Graduation in the University Honors Program, Pp. 7-33.

10. Jan Rottler, 2019. Mexican Embassy Berlin, URL https://janrottler.de/37c-mexicanembassy-berlin

11. Joseph Rykwert, 2014. In Mönchengladbach, Hans Hollein's Museum, URL https://www.domusweb.it/en/from-thearchive/2014/04/28/in_ma_nchengladbachthehansholleinsmuseum.html

12. Liu S, Hu R, Li Q, Zhou P, Dong Z, Kang R, 2014, Topology optimization-based lightweight primary mirror design of a large-aperture space telescope, Pp. 25-53.

13. Michael F. Ashby, 1999. Materials Selection Mechanical Design, Pp. 9-28.

14. Neri Oxman, 2010, Structuring Materiality Design Fabrication of Heterogeneous Materials, Architectural Design Journal AD, The New Structuralism Design, Engineering and Architectural Technologies, Wiley, URL https://onlinelibrary.wiley.com/doi/abs/10.1002/ad.1110

15. Peter Zumthor, 2020. Saint Benedict Chapel, URL http://architectuul.com/architecture/saint-benedict-chapel

16. Pshtiwan N. Shakor, S. S. Pimplikar, 2011, Glass Fiber Reinforced Concrete Use in Construction, International Journal of Technology and Engineering System.

17. Sharpe JEE, 1995. Computer tools for integrated conceptual design. Des Studies, P. 88.

18. Wilfredo Méndez, 2019. Structuring Biomimicry, Improving Building's Resiliency, URL http://ieet.org/index.php/IEET/print/6168

19. Xie YM, Steven GP, 1993, A simple evolutionary procedure for structural optimization. Comput Struct, P. 96.

20. Zhu J, Zhang W, Beckers P, 2009, Integrated layout design of multi-component system. Int J Numer Methods Eng, Pp. 51-78. 